\title{
El mundo del trabajo libre y esclavo en la campaña cuyana luego de la guerra de independencia argentina (Mendoza, 1823)
}

The world of free and slave labor in the Cuyo campaign after the Argentine war of independence (Mendoza, 1823)

\author{
Orlando Gabriel Morales \\ Instituto de Ciencias Humanas, Sociales y Ambientales / \\ CONICET, Argentina \\ omorales@mendoza-conicet.gob.ar
}

\section{Resumen:}

Este artículo explora las características de la población esclava, las ocupaciones y distribución de los trabajadores libres, especialmente los afrodescendientes, y el acceso a la propiedad en la campaña de Mendoza de la década de 1820. El objetivo es conocer la inserción de estos sectores en la estructura social posrevolucionaria. Consideramos que la revolución y la guerra introdujeron y profundizaron cambios económicos, políticos y sociales que impactaron en la integración de estos sectores sociales. Las fuentes examinadas, con herramientas de estadística descriptiva, son padrones de población y de propiedad de los vecinos de Mendoza de 1823. Los resultados muestran el impacto de la militarización en la esclavitud, la estructuración social posrevolucionaria en base a las ocupaciones y entregan indicios de la movilidad social de los afrodescendientes.

Palabras Clave: Trabajo, Esclavitud, Afrodescendientes, Campaña, Mendoza.

\begin{abstract}
:
This article explores the characteristics of the slave population, the occupations and distribution of free workers, especially Afrodescendants, and access to property in the Mendoza campaign of the 1820s. The objective is to know the insertion of these sectors in the post-revolutionary social structure. We consider that the revolution and the war introduced and deepened economic, political and social changes that had an impact on the integration of these social sectors. The sources examined, with descriptive statistics tools, are a population register and a property register of the residents of Mendoza from 1823. The results show the impact of militarization on slavery, post-revolutionary social structuring based on occupations and they provide indications of the social mobility of Afro-descendants.
\end{abstract}

KEYWORDS: Work, Slavery, Afro-descendants, Campaign, Mendoza.

\section{INTRODUCCIÓN}

Este trabajo explora el mundo del trabajo libre y esclavo en la campaña de Mendoza a partir del análisis y triangulación de variables sociales, económicas y étnico-raciales con datos brindados por un padrón de población y un padrón de fortunas de Mendoza de 1823, registros realizados luego de la revolución y guerra de la independencia argentina y en los primeros años de la autonomía provincial. Se examinan en particular la inserción social de los trabajadores afrodescendientes libres y las características de la población esclavizada de la campaña, en un momento histórico que permite ponderar el impacto de la militarización revolucionaria y de la extracción de recursos para la guerra durante la década de 1810, y los cambios en la estructuración social posrevolucionaria.

Conocer esas cuestiones permitirá entender mejor el proceso de integración social de la población africana y afrodescendiente en esta región rioplatense en el contexto de los procesos económicos, políticos y sociales desencadenados o profundizados por la revolución y la guerra de independencia en el Río de la Plata. 
La historiografía de la región refiere a una "crisis de la esclavitud" y de la mano de obra negra libre, dedicada a la agricultura, la producción de vinos y el servicio doméstico, con posterioridad a la intensa extracción de varones para la formación de cuerpos armados revolucionarios y del Ejército de los Andes (Comadrán Ruiz, 1972; Garavaglia, 2013; Garavaglia y Prieto, 2007; Masini Calderón, 1962, 1963).

Según los cálculos de Masini (1962), la población negra constituía el 33 por ciento del total de la población de Mendoza en 1812 y cayó al 12 por ciento en 1823. Un argumento común en la historiografía tradicional argentina sostiene que la población esclava y afrodescendiente en el Río de la Plata declinó hasta desaparecer como consecuencia de su participación en las guerras de independencia y las guerras civiles. Sin embargo, desde la década de 1980, luego de las interpretaciones de George Andrews (1989) sobre el declive demográfico y la "desaparición" de la población afroargentina de Buenos Aires, se han elaborado explicaciones más complejas sopesando otros factores, como la desmarcación étnico-racial y la movilidad social de los propios afrodescendientes, y los mecanismos clasificatorios censales, traslados estadísticos y discursos de las élites tendientes a crear un imaginario de nación excluyente de la afrodescendencia.

La historiografía argentina no ha prestado demasiada atención a los afrodescendientes en el espacio rural rioplatense, salvo por algunos aportes que contradicen la idea bastante común de que la presencia y mano de obra africana esclava y libre estaba acotada al espacio urbano y ubica a este sector entre los capataces, jornaleros y peones de campaña en distintas latitudes durante la colonia y las primeras décadas del período independiente (Ghirardi, Colantonio y Celton, 2010; Goldberg y Mallo, 2005; Moreno, 1989).

Hasta ahora se conoce muy poco sobre el mundo del trabajo libre y esclavo en la campaña posrevolucionaria de Mendoza, y menos todavía sobre la situación de los africanos y descendientes que trabajaron en las labores ligadas a la agricultura y ganadería en las fincas, haciendas y estancias. Una aproximación de Molina (2013) a la composición social de algunos cuarteles rurales por medio del padrón de 1814 dio cuenta de una segmentación socio-étnica de las ocupaciones, con una participación mayoritaria de "mulatos" y "mestizos" en el peonaje de la campaña. Además, en ese padrón, levantado con fines militares, la autora registró un número significativo de peones gañanes originarios de Chile vinculados a la ganadería (Molina, 2013). Se sabe también que algunas ocupaciones ligadas al transporte de los productos de la tierra y a la vitivinicultura fueron ejercidas desde la colonia por algunos afrodescendientes, que llegaron incluso a convertirse en maestros de oficios y propietarios (Lacoste, 2009).

Comadrán Ruiz (1972) ensayó una aproximación a la estructura demográfica y socioeconómica de Mendoza por medio del padrón de población de 1823 y del censo de fortunas de ca. 1823, ambas fuentes que nosotros analizamos aquí, pero prestó muy poca atención a la situación de los trabajadores y esclavizados. De todos modos, su estudió señaló para la campaña al menos dos aspectos significativos que contribuyen a nuestro análisis: el crecimiento demográfico -o mayor interés en el registro- luego de la revolución y del estancamiento de la primera década del siglo XIX, y la fragmentación de la propiedad rural en capitales pequeños.

Como se adelantó, el padrón de población de Mendoza de 1823 constituye la fuente principal de este estudio, que se valdrá también de un padrón de haberes y propiedades de los vecinos de Mendoza de ca. 1823. Ambas fuentes se hallan alojadas en el Archivo General de la Provincia de Mendoza (AGPM). ${ }^{1}$

En adelante, primero, se describen las fuentes documentales y la matriz de datos elaborada para su estudio. Luego se presenta una descripción del contexto económico, social y de la población de la campaña de Mendoza a fines del siglo XVIII y principios del XIX. Luego, en dos apartados, se exponen los resultados del análisis atendiendo, por un lado, a dar cuenta de la composición del mundo del trabajo esclavo y libre en la campaña hacia la década de 1820; y, por otro, a revisar las relaciones entre condición étnico-racial, ocupación y patrimonios. Por último, se exponen algunas consideraciones finales. 


\section{LAS FUENTES HISTÓRICAS}

En 1823 la ciudad de Mendoza estaba compuesta por 11 cuarteles urbanos y su campaña por 37 cuarteles rurales, que incluían los barrios de extramuros lindantes a la ciudad y villas y parajes lejanos. ${ }^{2}$ El padrón de población de Mendoza de 1823 se conserva en buen estado en el AGPM, aunque incompleto y alojado en dos carpetas distintas: $\mathrm{n}^{\circ} 14 \mathrm{y} \mathrm{n}^{\circ} 15$ de la sección Gobierno, fondo Época Independiente. No se conservan los documentos de los cuarteles $n^{\circ} 8$ de ciudad y 15, 34, 36 y 37 de campaña.

Masini (1962) y Comadrán Ruiz (1972) revisaron el detalle del padrón para contar la población y sus resultados difieren en el volumen total. Masini contó 17.734 habitantes y Comadrán Ruiz 18.792; la diferencia se debería a que no habrían localizado todos los documentos. Masini estimó el total de población entre 20 y 25.000 habitantes, mientras que Comadrán Ruiz calculó unos 20.188. Creemos que esta última ponderación es más precisa, pero algo inferior al volumen que debió representar el total, porque Comadrán Ruiz no consideró la existencia de al menos los cuarteles 34 al 37, la que consta en fuentes -ver nota $n^{\circ} 2$-.

El empadronamiento de la población fue solicitado por la Sala de Representantes de Mendoza el 25 de octubre de 1822, con la indicación de que se elaborara un "censo general de toda la población con especificación de sexo, edad, patria y ejercicio" (Comadrán Ruiz, 1972, p. 2). El propósito habría sido cuantificar la población para determinar la cantidad de diputados que deberían representar a Mendoza en el entonces proyectado Congreso General de las Provincias que se realizó en 1824/1825 (Peña y Lillo, 1937). Entre enero de 1823 y octubre de 1824 , los decuriones dieron cumplimiento a la orden de la Sala, refrendada por el gobernador Pedro Molina, y empadronaron a los habitantes de los cuarteles a su cargo. ${ }^{3}$

La mayoría de los decuriones de campaña relevaron todas las variables ordenadas por la Sala y registraron también el "estado" (matrimonial) de las personas. Algunos, además, incluyeron la variable "calidad" (condición étnico-racial), ${ }^{4}$ y otros hicieron mención de la "facultad” (propiedad) de los jefes de familia. No todos los decuriones, aunque sí la mayoría, organizaron sus registros por unidades familiares ("casa de"). De modo que los registros son algo heterogéneos y la confiabilidad de la información en general está condicionada por diferencias de criterios y ausencia de sistematicidad en el empadronamiento, algo común en la estadística colonial y del período republicano preindustrial en la América hispana (Cosamalón Aguilar, 2017).

Por otra parte, la Sala de Representantes de Mendoza también ordenó la elaboración de un padrón de haberes y propiedades de los vecinos con el propósito de establecer una contribución extraordinaria. Según Comadrán Ruiz (1972), ese registro se terminó de completar el 14 de enero de 1823. En ese documento, que se conserva en el AGPM catalogado "sin fecha", los decuriones (que no son los mismos que confeccionaron el padrón de población) registraron a jefes de familia de todos los cuarteles de la ciudad y de la campaña e indicaron un monto estimado de sus fortunas, sin especificar su composición.

Si se comparan los jefes de familia anotados en el padrón de patrimonios con los registrados en el de población se advierte que no hay una correspondencia estricta: algunos vecinos aparecen en un censo y no en el otro. Aunque en general hay coincidencia en el vecindario de los cuarteles y se trata de registros contemporáneos. Para mayor precisión, se cruzó información de algunos vecinos censados en el padrón de fortunas con sus registros vitales en fuentes eclesiásticas y se llegó a la conclusión de que ese relevamiento habría sido confeccionado entre 1821 y 1822 . El documento entrega información importante para este estudio en tanto sus registros se pueden triangular con el padrón de población.

En el diseño de la base de datos que recupera la información del padrón de población de Mendoza de 1823 se incorporaron las variables relevadas por los decuriones y se incluyó la mayor cantidad posible de la información disponible. Se ingresaron 6.585 registros correspondientes a catorce cuarteles de extramuros ( 1 , $2,6,12,13,17,18,20,21,23,24,27,32$ y 33$)$, lo que representa el 47,2 por ciento de los datos disponibles para la campaña (13.963 habitantes). 
Los cuarteles cargados en la base se distribuían en la geografía de la provincia de forma tal que son representativos de la diversidad de espacios productivos, económicos y sociales del ámbito rural mendocino de la época (ver Figura 1). Hay que decir, sin embargo, que se procuró que la base de datos contenga la mayor cantidad de población afrodescendiente, esclava y libre, para reunir más información que permita un análisis descriptivo denso de esos grupos.

FIGURA 1

Ubicación de cuarteles de campaña de 1823 en plano actual de Mendoza

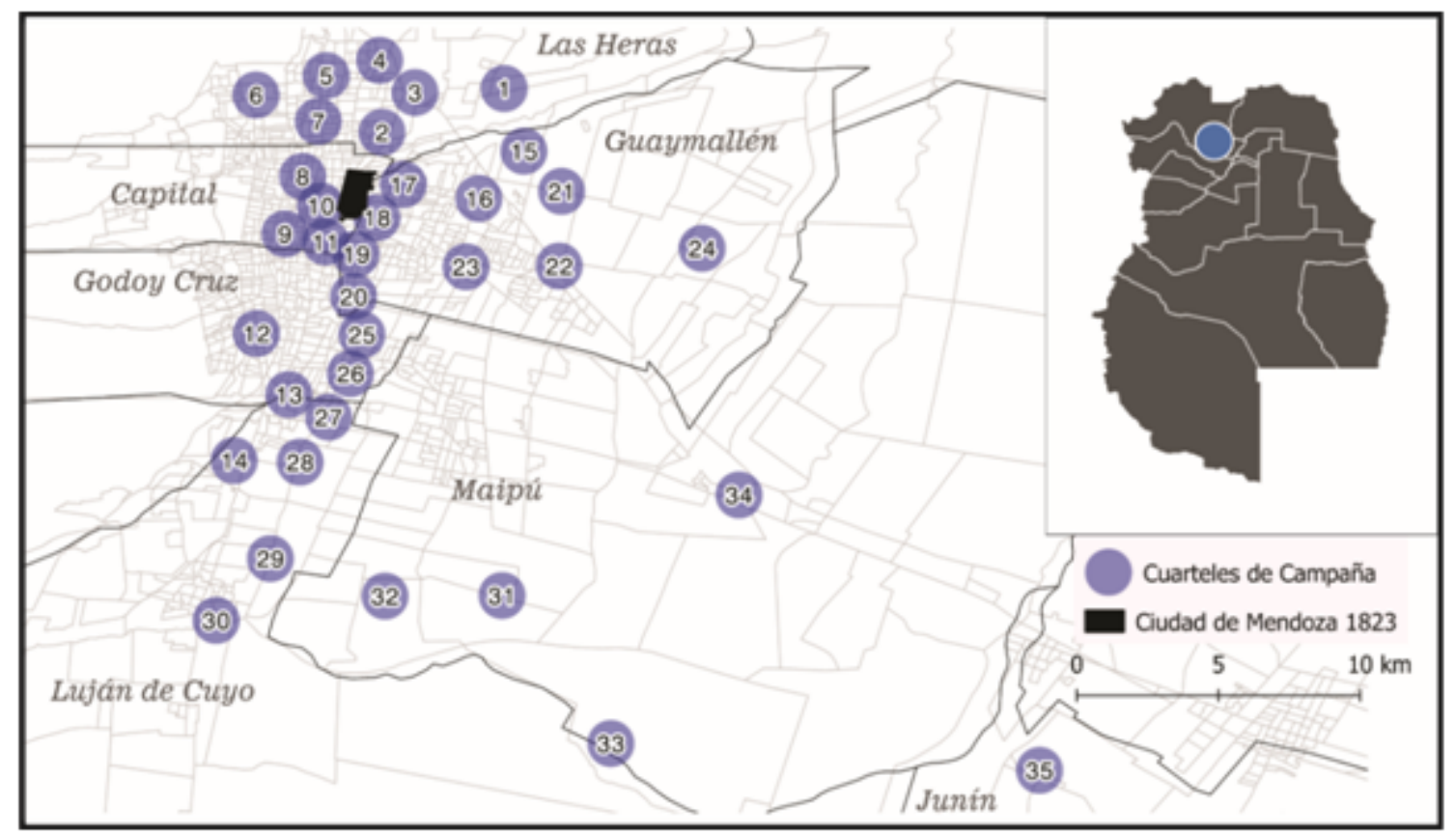

Fuente: Elaboración propia, con la colaboración de la Arq. Dra. Noelia Alchapar (INAHE,

CONICET), con base en el plano de 1814 publicado por Molina (2013) -ver nota n²-.

En la base de datos de población se cargaron 447 personas de la campaña registradas como esclavas, libertas o libres y marcadas como mulatas, pardas y negras; 183 anotadas como esclavas sin información de "calidad"; y, asimismo, otras 38 señaladas como libertas. De modo que la población esclava y afrodescendiente sin marcas de esclavitud de la campaña suma un total de 668 habitantes, algo más del 10 por ciento de la muestra. Evidentemente, el volumen absoluto de este grupo social en la campaña era mayor, porque los esclavos están calculados sobre el 47,2 por ciento que representa la muestra y los afrodescendientes, estimados a partir de los registros parciales de "calidad" disponibles (3.381 personas, un 24,2 por ciento del total de la campaña).

En este punto conviene señalar que algunos decuriones marcaron como esclavos/as a niños de entre 1 y 10 años, cuando en 1823 los hijos/as de esclavas de hasta 10 años debían ser "libertos" por disposición del Reglamento para educación y ejercicio de los libertos dictado por la Asamblea General de las Provincias Unidas en 1813 (Candioti, 2016). Los beneficiados por esa disposición recibieron la marca de "liberto" en registros vitales parroquiales y otras fuentes nominales desde 1813 (Alberto, 2020). En esos casos se corrigió la marca del decurión y se cargó a esas personas en la base de datos como libertas, con el propósito de ponderar de modo más preciso el volumen de ese grupo social en 1823. Además, algunos decuriones anotaron como libertas a personas mayores de 10 años que debían ser libres por automanumisión o por manumisión graciosa, es decir que- por su edad-su libertad no derivaba de la ley de vientres. Esos registros exponen un presupuesto compartido en el Río de la Plata sobre la condición "ambigua" de los libertos y la precariedad de su libertad (Alberto, 2020). 
Los registros del padrón de haberes y propiedades de los vecinos de Mendoza de ca. 1823 se incorporaron en otra base de datos en la que se ingresaron las variables relevadas por los decuriones: nombre, apellido y valor del patrimonio declarado. Luego de completar la base de patrimonios se hizo una copia en la que se agregaron las variables "calidad" y "ejercicio", retomadas del padrón de población de 1823, para informar esos valores en los casos de vecinos que contaban con esos datos. En total, se cuenta con 138 registros de vecinos de los cuarteles 1, 2, 18, 20, 21, 23, 24 y 32 de extramuros que se hallaron en ambos padrones. La triangulación permitió indagar la relación entre patrimonio, condición étnico-racial y ocupaciones.

\section{La CAMpaña de Mendoza a fines del Siglo XVIII y PRINCIPIOS DEL XIX}

La vitivinicultura y la industria asociada a la producción de vinos en Mendoza constituyeron la actividad económica principal y ocuparon una importante mano de obra esclava desde mediados del siglo XVIII hasta la primera década independiente (Garavaglia, 2013). En cambio, la actividad ganadera y la agricultura subordinada fueron creciendo en importancia y demandando progresivamente trabajadores en el siglo XIX. El comercio del ganado en pie que se engordaba en Mendoza y luego se trasladaba a Chile fue aumentando desde la década de 1810 y se extendió por varios decenios (Richard Jorba, 1998). También la actividad del transporte por arrias de mula y por carretas, que aprovechaba la ubicación de Mendoza en los caminos comerciales que conectaban a Buenos Aires, Valparaíso, Santiago y el Alto Perú, constituyó una importante fuente económica y de intercambios -no sólo comerciales-, que también involucró la circulación de esclavos y el trabajado de afrodescendientes libres (Lacoste, 2009).

La producción vitivinícola y el comercio local se vieron fuertemente afectados por la introducción del libre comercio desde fines del período colonial y más todavía en la primera década revolucionaria por la interrupción del camino del norte hacia el Alto Perú, la competencia de los mercaderes ingleses y la presión fiscal por la guerra (Acevedo, 1981; Halperin Donghi, 2014).

En los últimos años de la década de 1820 se produjo "un cambio profundo en la estructura productiva regional: el progresivo abandono de la viña y su remplazo por los potreros destinados a alfalfares" (Garavaglia y Prieto, 2007, p. 9) para el engorde de animales. La ganadería comercial avanzó sobre la agricultura, pero el cultivo de trigo y la producción de harina se sostuvo con la demanda de Buenos Aires, Córdoba y Santa Fe (Richard Jorba, 2001).

Hacia la década de 1860, cuando el modelo de la ganadería comercial se había consolidado y estaba en un período de auge, la inmigración chilena atraída por el mercado de trabajo rural hacía crecer en forma significativa el volumen de peones (Richard Jorba, 2001). Pero, como se dijo antes, la presencia de peones gañanes oriundos de Chile que convivían con esclavos y afrodescendientes libres en la campaña mendocina se registraba ya en el padrón de 1814 (Molina, 2013); y el fenómeno de la movilidad de estos trabajadores chilenos y cuyanos en la frontera sur de la América hispana se registraba ya en el siglo XVIII desde el Chile central, pasando por el espacio regional cuyano y hasta la campaña bonaerense (Garavaglia, 1999; Valenzuela Márquez, 2007).

En la primera mitad del siglo XIX la ciudad de Mendoza consolidó su posición nodal como lugar de tránsito y centro articulador de intercambio y distribución de bienes en los circuitos mercantiles entre el Atlántico y el Pacífico (Molina, 2013; Richard Jorba, 2001). En ese contexto, la ciudad organizaba el espacio económico articulando el oasis, favorecido por un sistema de riego artificial, y las zonas desérticas. Las haciendas, en el oasis, y las estancias, en el secano, constituían las unidades productivas dedicadas a la agricultura y el engorde de ganado y a la cría de animales, respectivamente (Richard Jorba, 2001). El mundo del trabajo en la campaña estaba organizado mediante el trabajo forzado y el trabajo libre regulado con formas de coacción, control y disciplinamiento.

La población de la campaña parece haber crecido de forma sustancial a principios del siglo XIX, pero hay que hacer algunas consideraciones. Si se observan los distintos registros de la población de la campaña de 
Mendoza desde mediados del siglo XVIII (ver Tabla 1), se puede advertir que existió una dificultad para contabilizar esa población, y que el volumen registrado debió depender del alcance del empadronamiento en el territorio y de la mayor o menor incorporación de la población indígena huarpe, distante y dispersa en el territorio controlado.

TABLA 1

Población de la ciudad y la campaña de Mendoza, siglos XVIII y XIX

\begin{tabular}{|c|c|c|c|}
\hline Año & Ciudad & Campaña & Total \\
\hline 1753 & - & 1.261 & - \\
\hline $1777 / 8$ & 7.478 & 1.287 & 8.765 \\
\hline 1785 & 9.232 & 866 & 10.098 \\
\hline 1802 & 13.681 & - & 13.681 \\
\hline 1812 & 5.487 & 7.831 & 13.318 \\
\hline 1823 & 5.218 & 13.574 & 18.792 \\
\hline
\end{tabular}

Fuente: Años 1753, 1777/8, 1785, 1802 y 1812, Comadrán Ruiz (1969); año 1823, Comadrán Ruiz (1972)

Comadrán Ruiz (1969) atribuye el casi nulo crecimiento de la campaña entre 1753 y 1778 al recrudecimiento de los malones indígenas en la frontera sur de Mendoza. Sostiene que el posterior aumento de la población rural se debió a la política de control de los grupos indígenas, especialmente entre 1783 y 1800, que desarrolló, a través del comandante Francisco de Amigorena, el marqués Rafael de Sobremonte, primero al mando de la Intendencia de Córdoba del Tucumán y luego del Virreinato del Río de la Plata (Comadrán, 1969: 97-98).

La comparación de los registros oficiales de la década de 1810 y 1820 muestra un crecimiento significativo de la campaña, que posiblemente expresa también un nuevo interés político por el registro y control de la población rural, en línea con un fenómeno de ruralización de las bases del poder luego de la crisis política de 1820 en el Río de la Plata (Halperin Donghi, 2014). Sin embargo, Richard Jorba (2001) considera que hasta fines del XIX la población de Mendoza creció con lentitud y la inmigración fue poco relevante, salvo por la procedente de Chile, hecho que contribuyó a que el mercado de trabajo rural se acotara a los pequeños propietarios y a los que sólo aportaban "la fuerza de sus brazos" (2001, p. 9).

Los datos de la muestra sobre el origen de las personas, registrados en el padrón de población de 1823 en la variable "patria", indican que el 80 por ciento de los habitantes habían nacido en Mendoza. La migración chilena era la más relevante y representaba el 8,2 por ciento de la población. Esa presencia y su integración local era evidente, al menos entre 1800 y 1840, en el volumen de los matrimonios contraídos entre chilenos y mendocinas (Cremaschi, 1989). Por su parte, los que provenían de San Luis y San Juan sumaban el 6,5 por ciento y llegaban al 8 por ciento incluyendo a los de Córdoba. Los "africanos" (marcados también con las categorías "mina", "moro", "angola”, "guinea”) eran apenas el 0,5 por ciento.

Por otra parte, el hecho de que durante el empadronamiento no todos los decuriones de los barrios y villas de la campaña hayan registrado la "calidad" de las personas imposibilita conocer los valores de la variable para toda la población. En la base se cuenta con información acerca de la "calidad" para los habitantes de los cuarteles 1, 2, 18, 20, 21, 23, 24, 27 y 32 de extramuros, que suman 3.381 personas $(n=3.356$, descartando los ilegibles y sin información). Esos datos indican que la población marcada como "española" era mayoría: 55 por ciento. Pero los no españoles sumaban el 45 por ciento, con una importante presencia de "mestizos", "pardos" y "mulatos", 28 por ciento, seguidos por los "indios", 15 por ciento, y muy pocos marcados como "negros", 2 por ciento. 
Es posible que el volumen del grupo "español” esté indicando un fenómeno de pasaje de los "mestizos", lo que puede interpretarse como una devaluación de la categoría. Los considerados "españoles" eran en su mayoría criollos, los que declararon ser originarios de ciudades españolas apenas sumaban el 0,4 por ciento del total y los "europeos", el 1,2 por ciento. Es muy posible que la movilidad social en la campaña contribuyera a la posibilidad de pasaje en la marcación étnico-racial, especialmente para los mezclados. El mestizaje de los negros en Mendoza era intenso ya a mediados del siglo XVIII. Cremaschi (1989), quien estudió los matrimonios contraídos en el período 1800-1840, calculó un 22 por ciento de uniones con consortes "pardos", "mulatos" y "negros". Masini, por su parte, llegó a asegurar que los datos de 1823 expresaban que el "grupo blanco", que según su interpretación representaba el 81 por ciento del total de la población, mostraba una "tendencia igualitaria" por la incorporación de gente de color (1962, p. 15).

\section{ESCLAVITUD Y TRABAJO LIBRE EN LA CAMPAÑA HACIA LA DÉCADA DE 1820}

La población esclavizada en 1823 estaba constituida, según la muestra (213 personas), por 39,4 por ciento de varones y 60,6 por ciento de mujeres. La mitad de esa población era soltera y poco menos del 30 por ciento estaba casado. El promedio de edad del grupo era de 28 años, con un mínimo de 11 y un máximo de 78 años. El desequilibrio entre los sexos era notoriamente mayor a partir de los 25 años de edad (ver Figura 2), lo que da cuenta de las consecuencias de la extracción de varones mayores de 14 años para la guerra luego de 1810 y especialmente desde los rescates de 1813. Los varones de 60 años o más aventajaban en cantidad a las mujeres: eran los que por su edad y condiciones físicas habían sido exceptuados del servicio de las armas. Esta cohorte evidenciaba que en un período anterior la presencia esclava masculina había sido dominante, como era esperable en un área rural.

El porcentaje de población esclavizada en la campaña representaba el 2,6 por ciento, mientras que en la ciudad los esclavos constituían el 6,4 por ciento. Los cuarteles de extramuros con mayor cantidad de esclavos ( 17 y 13, en ese orden) eran cercanos a la ciudad, en tierras irrigadas dedicadas a la agricultura.

La mayor parte de los esclavos y esclavas había nacido en Mendoza, 78 por ciento, y sólo un 7,5 por ciento eran originarios de África. Los emigrados de otras ciudades del Río de la Plata representaban el 11,3 por ciento, y los de Chile, apenas el 0,9 por ciento. En este punto hay que advertir que según Masini (1962) la prohibición de la trata de esclavos en las Provincias a partir de 1812 tuvo más efecto en Cuyo que en otras regiones, donde continuaron ingresando africanos. Por esa misma razón, la introducción de esclavos a Mendoza dependía del comercio interno, y es probable que la crisis económica en las ciudades de Cuyo no favoreciera ese mercado.

En los cuarteles donde se registró la "calidad" de las personas, 17 esclavos fueron marcados como "negros", 9 “pardos” y 19 "mulatos”, de modo que la mayoría eran afrodescendientes mestizados, 62,2 por ciento. 
FIGURA 2

Pirámide de población afrodescendiente

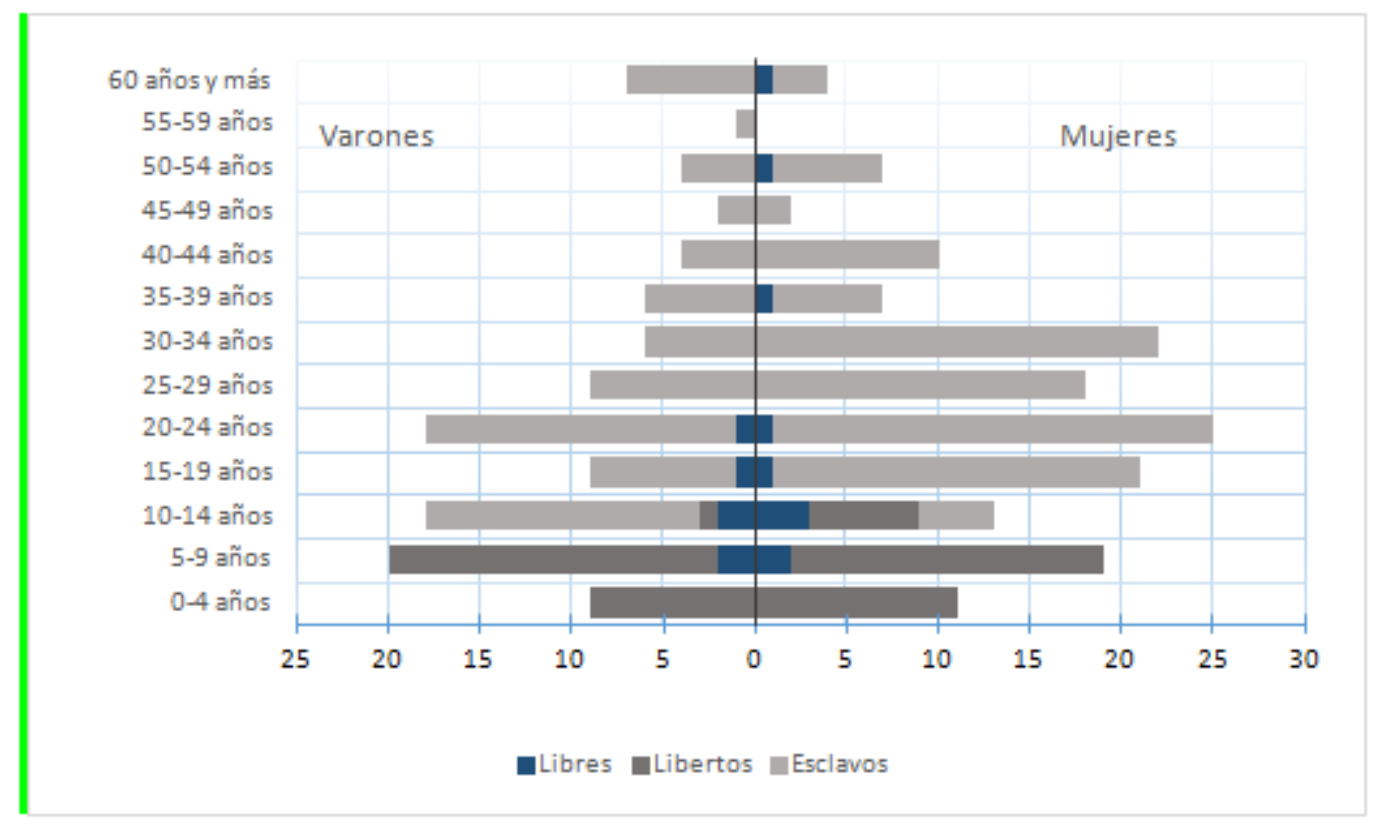

Fuente: Elaboración propia

Es importante advertir que el decurión del cuartel $\mathrm{n}^{\circ} 1$ de extramuros debió anotar a los esclavos como "criados", aunque para sujetarnos estrictamente a las categorías de las fuentes hemos respetado su clasificación. El cuartel n ${ }^{\circ} 1$ de campaña es el único de la base de datos que registra "criados". Un fenómeno similar de registro de los esclavos como "criados" detectamos en los cuarteles 3 y 7 de la ciudad, lo que permite suponer que algunos factores pueden haber incidido para que los esclavos estuviesen siendo registrados con esa categoría. Sin embargo, hay que advertir también que en algunos cuartes se registraron criados marcados como "libre".

Las consecuencias de esta práctica pueden haber favorecido tanto la subestimación cuantitativa como la apreciación de declinación de los esclavos, que de todos modos fue acertada. Pero la falta de advertencia sobre este aspecto en la literatura histórica local merece atención. La ambigüedad en el uso de la categoría de criado y su vinculación con la esclavitud en el contexto abolicionista rioplatense ha sido señalada por Alberto (2020) para un estudio de caso en Buenos Aires. Garavaglia (1999), por su parte, señala que, después de 1810, en la campaña bonaerense algunos censos comenzaron a cambiar la denominación de "esclavos" por "criados".

Se puede suponer que los factores que llevaron a la clasificación de esclavos como criados se vinculaban con un criterio tradicional que conceptualizaba a estos últimos como sirvientes, convivientes y dependientes del jefe de familia, que realizaban distintas tareas, no sólo domésticas, en la casa habitación. Bernand (2001) sostiene que en Hispanoamérica los esclavos eran parte de los criados y señala que la estructura del linaje en la colonia implicaba "la cohabitación en la casa señorial de personas dependientes, los 'criados '” (Bernand, 2001). Para el caso de San Miguel de Tucumán de fines del siglo XVIII, Zamora (2010) estima que probablemente la categoría de "criados" no haya sido estrictamente laboral, porque los criados, esclavos y servidumbre estaban incluidos en la familia, bajo el gobierno del señor de la casa. Es decir, en el ámbito de la oeconomía o gobierno de la casa.

En términos económicos, los criados estaban sometidos en general al régimen de retribución de los esclavos: no percibían ingreso monetario sino la provisión de bienes y alimentos para la subsistencia.

Los registrados como "criados" en el cuartel n 1 suman 48 personas, 26 varones y 22 mujeres, todos nacidos en Mendoza. Ninguno recibió una marca que indicase su relación con la libertad civil. La mayoría de estas 
personas eran solteras (21), sólo 7 habían contraído matrimonio y el resto eran párvulos (16). En la medida que el decurión marcó la "calidad" sabemos que el 78,7 por ciento de estos "criados" eran "pardos" y que los "negros" sumaban 21,3 por ciento. Como en el caso de los esclavos (excepto por un zapatero), a los criados no se les anotó una actividad, ejercicio u oficio. La ausencia de una especialización indica que esclavos y criados eran mano de obra para todo tipo de servicios. Los datos de edad también indican equivalencia en estos dos grupos. El promedio de edad de los criados era de 27 años, con un máximo de 80 y un mínimo de 1 año.

Por su parte, los hijos de los esclavos nacidos libertos por el Reglamento de marzo de 1813 constituían en 1823 un grupo social diferenciado por buena parte de los decuriones con esa categoría. Los "libertos" suman en la muestra de la campaña 75 personas, 32 varones y 43 mujeres, con un promedio de 6 años de edad, casi todos nacidos en Mendoza (71). ${ }^{5}$ Su distribución en los cuarteles indica que en general debieron convivir con sus progenitores, lo que era obligatorio por reglamento sólo hasta cumplidos los dos años de edad. En su mayoría fueron marcados como "mulatos" y "pardos" (68 por ciento).

Masini (1962, pp. 66-67) sostiene que el Reglamento de libertos no se cumplió en Cuyo; incluso, que el liberto experimentó una servidumbre prolongada, el comercio y la explotación económica de su trabajo. El uso de la categoría "esclavo" para marcar a algunos libertos podría ser un indicio en tal sentido.

En cuanto al grupo registrado con la condición de "libre", su volumen es llamativamente pequeño. Si se considera el tamaño de la población afrodescendiente, parece claro que muchos libres no fueron marcados como tales. Los libres en la muestra suman 16 personas, 6 varones y 10 mujeres, casi todos criollos (15), a excepción de 1 guineano. El promedio de edad del grupo es de 20 años y la edad mínima de 6 años. Este dato llama la atención porque para la población en general los decuriones registraron incluso a los recién nacidos. Pero hay más datos significativos, porque en el Río de la Plata en general la categoría de "negro" estaba más estrechamente asociada a la esclavitud que la de "mulato", pero en este caso el 76,9 por ciento de los "libres" fueron identificados como "negros" y sólo el 23,1 como "pardos" y "mulatos". Dicho lo anterior, hay que advertir que los libres fueron localizados sólo en 3 cuarteles, donde fue anotado también un buen número de criados y esclavos. Estos aspectos inducen a hipotetizar que estos "negros" y "mulatos" libres necesitaban distinguirse con un atributo crucial en un espacio social abigarrado.

Otra posibilidad de distinción social entre los trabajadores libres era ofrecida por las categorías asociadas a la especialización y dedicaciones. Hay que considerar también estas categorías como dinámicas (Garavaglia, 1999), aunque ese fenómeno no se puede detectar sin triangular distintas fuentes para detectar cambios en las autocalificaciones ocupacionales.

En el oasis del norte, la zona mejor representada en los cuarteles de extramuros que analizamos, se desempeñaban peones permanentes, temporarios y trabajadores a destajo. Los peones empleados en las haciendas de forma permanente se dedicaban a tareas comunes y cotidianas. En cambio, los trabajadores temporarios se empleaban para la cosecha de cereales y frutos entre los meses de diciembre y mayo. Como lo señala Richard Jorba (2001), para un período posterior, pero que no debió ser muy diferente del que estudiamos, durante la cosecha los trabajadores de los sectores populares de la ciudad ofrecían su mano de obra en la campaña. Más tarde, entre los meses de mayo y el comienzo de la primavera, la actividad agrícola disminuía y los arrieros introducían ganado desde el Este para su engorde en los alfalfares.

Considerando esos escenarios estacionales, es importante hacer notar que en los cuarteles 21, 23 y 24, donde en 1823 se registró el mayor volumen de jornaleros, los padrones se elaboraron en los meses de febrero ( 21 y 24) y mayo (23). Asimismo, en los cuarteles 1,13 y 17, donde se registró más cantidad de peones, el relevamiento se efectuó en enero, abril y febrero, respectivamente. En estos mismos meses se censaron los cuarteles donde fueron empadronados más artesanos (13, 17 y 18$)$.

Los peones constituían el grupo de trabajadores más numeroso de la campaña, con un total de 582 . En la muestra contamos con información de 543 mayores de 14 años, es decir, en edad de trabajar y recibir una retribución por esa actividad. Se anotaron también 39 menores de 14 años, que por su edad se supone que no recibían salario sino que contribuían al trabajo de sus progenitores. Los peones solteros eran mayoría 
(329) y casi duplicaban a los casados (186). El promedio de edad entre los peones era de 31 años. Casi la mitad de los peones, 44,6 por ciento, eran originarios de Mendoza. Mientras que el 32 por ciento de ellos provenía de ciudades de Chile, un dato que muestra la continuidad en el tiempo del fenómeno de movilidad de trabajadores chilenos registrado para el año 1814 (Molina, 2013) y también para el período de auge de la ganadería comercial (Richard Jorba, 2001). La movilidad entre las ciudades de las Provincias Unidas aportaba el 13,4 por ciento de los peones. El peonaje comprendía a personas consideradas "españolas", 42 por ciento, pero mayoritariamente a personas mezcladas, que representaban el 52 por ciento. Los "indios" constituían el 4,6 y los "negros" el 1,4 por ciento.

El segundo grupo más voluminoso de trabajadores libres era el de los jornaleros: 251 mayores de 14 años y 56 menores. La edad promedio de los jornaleros, incluyendo a los menores de 14 años de edad, era de 27 años. Si bien la mayoría de los peones eran solteros (131), los casados constituían un grupo con casi el mismo volumen (109 personas). Es evidente que muchos jóvenes y párvulos acompañaban a sus familiares mayores en el trabajo. El 63,5 por ciento de los peones de la muestra eran originarios de Mendoza, el 17, 9 por ciento procedían de ciudades de Chile, y 15 por ciento de ciudades de las provincias del Río de la Plata. Entre los jornaleros se destacaban los considerados "indios", porque sumaban el 51,3 por ciento del total. La categoría “español" representaba el 28,8 por ciento; y "mulato", "pardo" y "mestizo" el 19,6 por ciento.

Los artesanos de la campaña ingresados en la muestra suman 151 varones, de los cuales 1 era esclavo. Fueron anotados sólo 3 menores de 14 años. En el grupo de artesanos predominaban los carpinteros (40), zapateros (36), albañiles (11), herreros (9) y sombrereros (9). El 65,6 por ciento de los artesanos se concentraba en tres cuarteles: 13, 17 y 18. En los dos primeros compartían el espacio laboral con un buen número de esclavos y peones. El promedio de edad de los artesanos era de 33 años. Se anotaron aprendices de hasta 9 años. El 55 por ciento tenía entre 20 y 34 años. La mayoría de ellos, el 60,3 por ciento, estaba casado. Es el único grupo de los descritos en que los casados superan ampliamente a los solteros ( 31,8 por ciento). Ese sería un indicio de su mejor posición social, con mejores posibilidades de formar una familia y constituirse en jefe de hogar.

El 60,9 por ciento de los artesanos eran originarios de Mendoza, el 15,2 por ciento eran migrantes chilenos y el 14,6 provenía de ciudades de la región del Río de la Plata. Las marcaciones de "calidad" disponibles indican que los artesanos considerados "españoles" representaban el 66,7 por ciento y los tenidos por "pardos" y "mulatos" el 21,7 por ciento. También había artesanos identificados como "indios", el 8,7 por ciento, y algunos "negros", 2,9 por ciento.

Los sirvientes, por otra parte, constituían un grupo muy reducido, compuesto por 10 varones y 11 mujeres mayores de 14 años. También fueron anotados como sirvientes 6 niños y 6 niñas. El 60 por ciento de los sirvientes tenía entre 10 y 24 años, y el promedio de edad del grupo era de 18 años. Casi la mitad de ellos convivían con la familia a la que servían. En su mayoría eran oriundos de Mendoza, el 81,8 por ciento; el resto provenía de ciudades cercanas, incluso de Chile. Sólo 14 sirvientes recibieron una marca de "calidad", que indica que esa actividad era realizada por “indios", 42,9 por ciento, "mestizos", 35,7 por ciento, y "españoles”, 21,4 por ciento.

\section{RELACIÓN ENTRE CONDICIÓN ÉTNICO-RACIAL, OCUPACIÓN Y PATRIMONIOS}

Como se ha dicho, la posibilidad de constituirse en jefe de familia y sostener un hogar era una forma de demostrar capacidad económica. Los decuriones de los cuarteles 1, 2, 18, 20 y 32 de extramuros organizaron sus registros diferenciando cada casa e indicando los jefes de familia; además, incluyeron la variable "calidad". En esos cuarteles registraron un total de 304 unidades censales que sumaban 1956 habitantes. Al cruzar los datos se obtiene que los varones "españoles" jefes de familia sumaban 199 (153 varones y 46 mujeres). Los "mestizos", "mulatos" y "pardos" sumaban 93 (60 varones y 33 mujeres), los "negros", 8 (5 varones y 3 mujeres) y los "indios" 4 (3 varones y 1 mujer). El caso de las mujeres jefas de hogar afrodescendientes expone un fenómeno interesante al mostrar mayor equilibrio entre los sexos. 
La posibilidad de ser jefe de familia estaba asociada a atributos como la ocupación o la actividad económica. El aprendizaje de un oficio era un atributo social de gran valor para las personas de los sectores plebeyos. El oficio implicaba la posibilidad de una mejor inserción socioeconómica y de movilidad social. Los datos de condición étnico-racial de los artesanos indican que los identificados como "españoles" tenían más acceso a los oficios o que, desde otra perspectiva, el ejercicio de un oficio, probablemente sumado a otros atributos sociales, habilitaba el acceso a la etiqueta mejor valorada socialmente. Entre los artesanos de la muestra, los considerados "negros" eran minoría (2,9 por ciento); incluso los "indios" (8,7 por ciento) triplicaban la participación de los "negros". Los "mestizos", en cambio, podían tener mejores expectativas. En cualquier caso, no todos los oficios requerían la misma disponibilidad e inversión de recursos (conocimientos, habilidades, herramientas) ni otorgaban el mismo prestigio social. Mientras que un platero podía tener un patrimonio importante en bienes de producción (herramientas, esclavos, bienes terminados y materias primas), un zapatero, por lo general, apenas reunía una fortuna modesta y sus bienes de producción no representaban un capital importante (Johnson, 2013).

Los artesanos jefes de familia de la muestra suman 87 , el 57,6 por ciento del total. Sólo tenemos marcas de condición étnico-racial para 40 de ellos, de los cuales 27 eran "españoles", 8 "pardos" y "mulatos", 3 "indios" y 2 "negros". Los jornaleros jefes de familia suman 104, el 33,9 por ciento del total, divididos en 57 "indios", 35 “españoles", y 12 "pardos" y "mulatos". Mientras que los peones jefes de familia suman 125, el 21,5 por ciento del total. Sólo tenemos marcas de condición étnico-racial para 57 de esos peones, 28 eran "pardos" y "mulatos”, 25 “españoles" y 4 “indios”. En síntesis, los artesanos tenían más posibilidades de convertirse en jefes de hogar que los jornaleros y los peones. Además, posiblemente, si se contaba con un oficio artesanal y se reunían otros atributos era plausible que fuera considerado "español".

Los escasos datos sobre propiedad que tenemos en la muestra por el registro que excepcionalmente realizaron los decuriones de los cuarteles 1 y 18 de extramuros permiten ponderar la distribución por condición étnico-racial del acceso a las propiedades (Ver Tabla 2). Los dos cuarteles reunían un total de 1.221 personas, divididas en 190 hogares. Allí no se registraron personas "agregadas", tampoco "inquilinos". Como se puede observar en la tabla, a menos de la mitad de los hogares se les anotó una propiedad. Entre los propietarios son mayoría los marcados como "españoles", pero los propietarios considerados "pardos" y "mulatos" también suman un volumen importante. La principal diferencia entre estos grupos pasaba por el tipo de propiedad: los "españoles" estaban en una posición dominante por su participación hegemónica en la propiedad de haciendas. Las personas afrodescendientes equiparaban a los "españoles" en la propiedad de sitios modestos de bajo estatus. Pero, a diferencia de aquellos, los afrodescendientes debían tener menos expectativas de alcanzar algo mejor porque la mayoría apenas alcanzaba a tener un sitio pequeño. La mayor desigualdad se manifiesta en relación con los marcados como "indios" y "negros", que no tienen siquiera acceso a uno de los tipos de propiedades de menor valor.

TABLA 2

Condición étnico-racial de los propietarios

\begin{tabular}{|l|c|c|c|c|c|}
\hline \multicolumn{1}{|c|}{ Propietarios } & Españoles & Indios & Negros & $\begin{array}{c}\text { Pardos } \\
\mathbf{y} \\
\text { mulatos }\end{array}$ & Total \\
\hline Hacienda & 23 & - & - & 2 & 25 \\
\hline Finca & 1 & - & - & - & 1 \\
\hline Sitio & 8 & - & - & 8 & 16 \\
\hline Sitio pequeño & 18 & - & - & 17 & 35 \\
\hline Casa y sitio & - & - & - & 2 & 2 \\
\hline Total & 50 & 0 & 0 & 29 & 79 \\
\hline
\end{tabular}

Fuente: Elaboración propia. Cuarteles 1 y 18 
Con algunos datos disponibles en la muestra del padrón de población también se puede evaluar el acceso a la vivienda y a la propiedad según el ejercicio o actividad económica declarada (ver Tabla 3). Se cuenta con datos para los cuarteles 1,17 y 18, que suman 2.571 personas, agrupadas en 387 hogares. Tenemos un total de 407 registros con datos acerca de la relación con la vivienda ocupada. Unos 310 registros corresponden a personas que vivían como agregadas y apenas 97 eran propietarios. Las propiedades censadas fueron hacienda, finca, sitio, sitio pequeño, casa o casa y sitio. ${ }^{6}$ La gran cantidad de registros sin datos de ejercicio (323) dificulta y limita el análisis que proponemos. En general, la propiedad se registraba asociada al jefe de familia, y el ejercicio, sólo para los varones. De modo que para las mujeres jefas de familia no se indicaba el ejercicio. Por eso, en algunos casos de propietarios para los que desconocemos el ejercicio puede tratarse de las 123 mujeres jefas de hogar (73 viudas, 31 casadas y 15 solteras) registradas en estos cuarteles.

En principio hay que señalar que el volumen de personas que fueron registradas como "agregadas" puede ser indicativo de las dificultades económicas de algunas familias. La familia agregada incorporaba a otros individuos, en algunos casos parientes (hermanas/os, primas/os, abuelas/os), que podían contribuir a la formación del ingreso familiar. Garavaglia (1999) sostiene que el agregado era un individuo en condición de dependencia con el jefe de familia pero que no necesariamente era un trabajador dependiente.

En este caso, de un total de 310 agregados una fracción de 134 eran menores de 14 años, de modo que probablemente no trabajaban o no percibían remuneración. Además, 145 agregados mayores de 14 años aparecen sin ejercicio, de los que 114 eran mujeres. El resto lo componen 31 varones en edad de trabajar, pero sin indicación de ejercicio, todos del cuartel 17.

Los datos acerca de los artesanos indican que la mayoría vivía como agregados en familias, 62,5 por ciento, probablemente en la misma casa habitación que funcionaba como unidad de producción, donde desarrollaban su actividad económica. La misma situación se observa para el caso de los peones, aunque para estos el porcentaje de agregados es todavía mayor, 72 por ciento. Los jornaleros directamente no aparecieron en el registro. Los artesanos y los peones fueron registrados también como propietarios de viviendas de bajo estatus: sitios y sitios pequeños. La mayor presencia (frecuencia absoluta) de los peones sobre los artesanos en los registros puede asociarse al volumen de ese grupo. 
TABLA 3

Acceso a la vivienda y la propiedad

\begin{tabular}{|l|c|c|c|c|c|c|c|c|}
\hline \multicolumn{1}{|c|}{$\begin{array}{c}\text { Acceso / } \\
\text { ejercicio }\end{array}$} & \multicolumn{7}{|c|}{ Acceso a la vivienda y la propiedad } \\
\hline \multicolumn{1}{|c|}{ Ejercicio } & Agregado & Hacienda & Finca & $\begin{array}{c}\text { Sitio } \\
\text { pequeño }\end{array}$ & Sitio & Casa & $\begin{array}{c}\text { Casa } \\
\text { y sitio }\end{array}$ & Total \\
\hline Labrador & - & 5 & - & 3 & 2 & 1 & - & 11 \\
\hline Peón & 18 & - & - & 5 & 2 & - & - & 25 \\
\hline Arriero & 1 & 2 & - & 3 & 1 & 1 & - & 8 \\
\hline Militar & - & 1 & - & - & - & - & - & 1 \\
\hline Pulpero & - & - & - & 3 & - & - & 2 & 5 \\
\hline Capataz & - & - & - & - & 1 & - & - & 1 \\
\hline Hacendado & - & 8 & - & - & 2 & - & - & 10 \\
\hline Artesano & 10 & - & - & 2 & 2 & - & 2 & 16 \\
\hline Comerciante & - & - & - & - & - & - & - & 0 \\
\hline Carretero & 1 & - & - & - & - & - & 1 & 2 \\
\hline Tropero & - & - & - & - & - & - & 1 & 1 \\
\hline Abastecedor & - & - & - & 1 & - & - & 2 & 3 \\
\hline Pescadero & 1 & - & - & - & - & - & - & 1 \\
\hline Sin precisar & 279 & 8 & 1 & 17 & 5 & 1 & 12 & 323 \\
\hline Total & 310 & 24 & 1 & 34 & 15 & 3 & 20 & 407 \\
\hline
\end{tabular}

Fuente: Elaboración propia. Cuarteles 1, 17 y 18

Por otra parte, el análisis del padrón de haberes y propiedades de ca. 1823 de los vecinos de la campaña, a partir del cotejo con el padrón de población, entrega algunos datos de interés, aunque las muestras obtenidas son pequeñas como para realizar conclusiones definitivas.

El cálculo sobre 88 registros de vecinos con patrimonios para los que se obtuvieron datos de ejercicio, correspondientes a los cuarteles 1,2,18,20,21,23, 24 y 32, permite obtener una representación general de la distribución de patrimonios acumulados por ejercicio o actividad económica (ver Figura 3).

El primer factor a considerar es la cantidad de propietarios por ejercicio, lo que indica quiénes tenían más posibilidades de ser parte del grupo de vecinos con patrimonios, independientemente del volumen de capital de cada grupo. Labradores, transportistas y hacendados, en ese orden, son los más representados. Es claro que los sectores de la producción dominaban la acumulación. Los hacendados acumulaban el mayor volumen de fortunas, seguidos por los labradores, los transportistas y los artesanos. Para una perspectiva desde la condición étnico-racial de los hacendados y labradores, se puede mencionar que en la muestra del padrón de población contamos con 90 hacendados registrados, 58 sin datos de condición, 30 marcados como "españoles" y 2, "mulatos". Mientras que los labradores registrados suman 341, con 121 sin datos, 176 considerados "españoles", 23 "pardos" y "mulatos", 20 "indios" y 1 "negro".

El sector de servicios tenía menor peso en las fortunas que el de la producción, con los transportistas (carreteros, troperos y arrieros) a la cabeza, seguidos por los jornaleros. Unos 7 jornaleros reunían 3.800 pesos. Es un dato llamativo si se considera que en el padrón de población no aparecieron como propietarios, al menos en los cuarteles 1, 17 y 18 . El promedio por jornalero censado es de 542,9 pesos y el patrimonio más frecuente declarado es de 100 pesos. Para el caso de la campaña bonaerense, Garavaglia (1999) señala que la frontera entre la categoría de jornaleros y la de labradores era móvil; quizás eso explica algunos patrimonios nada desdeñables en la campaña mendocina. En lo que respecta a los peones, su participación en el volumen 
de fortunas de la campaña era más marginal: 5 peones reunían un total de 800 pesos, con un promedio de 160 pesos por declarante, y el capital más frecuente era de 100 pesos.

FIGURA 3

Distribución de patrimonios

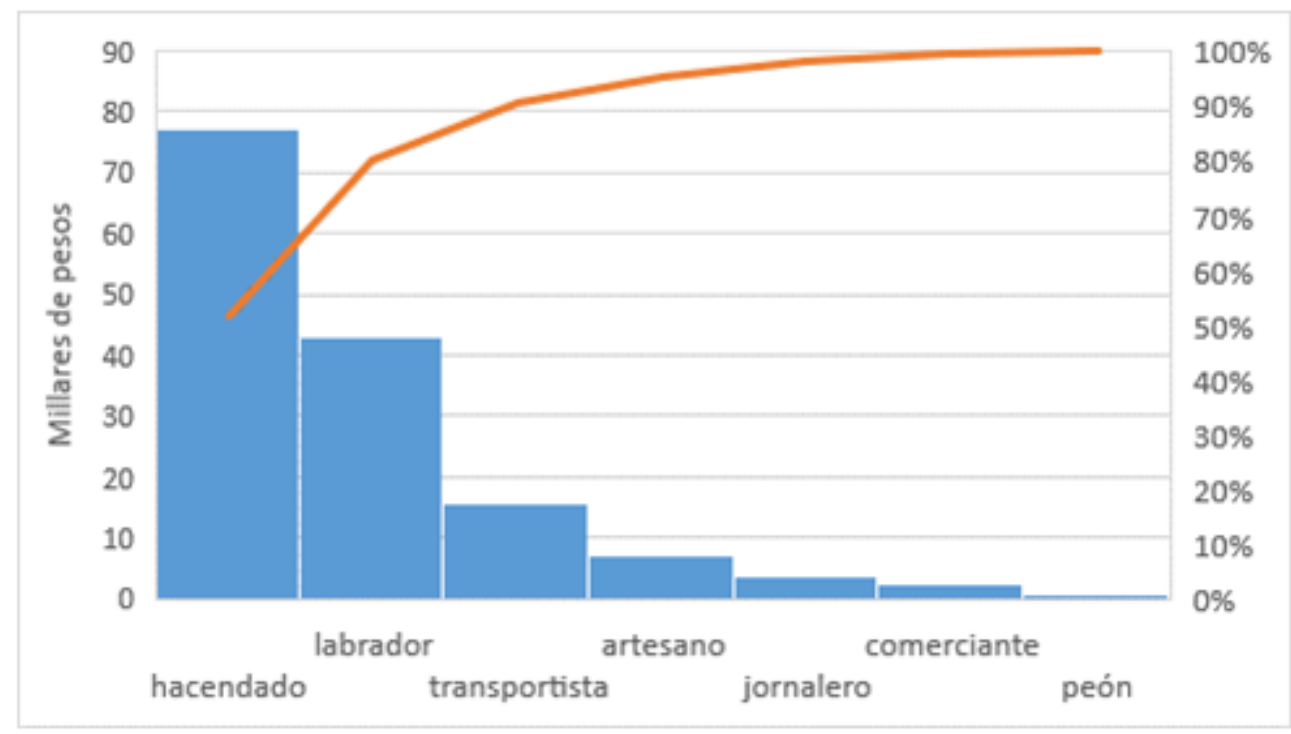

Fuente: Elaboración propia. Hacendados $n=14$. Labradores $n=31$. Transportistas $n=16$. Artesanos $n=9$. Jornaleros $n=7$. Comerciantes $n=5$. Peones $n=5$

En un segundo cálculo se buscó establecer la relación entre los patrimonios y la condición étnico-racial de los censados. Se procesaron 138 registros del padrón de haberes y propiedades, correspondientes a los cuarteles 1, 2, 18, 20, 21, 23, 24 y 32, para los que se obtuvieron datos de "calidad" en el padrón de población. Cabe aclarar que, para una mejor representación gráfica (Figura 4), todos los valores iguales o superiores a 5.000 pesos se agruparon en ese valor; y, por otra parte, que el padrón no registró patrimonios menores a 100 pesos.

Con base en el mismo padrón, Comadrán Ruiz (1972) calculó que en la campaña 811 vecinos acumulaban un total de 1.597 .000 pesos, mientras que en la ciudad las fortunas eran más cuantiosas: 551 jefes de familia sumaban 2.860 .900 pesos.

La representación de los datos que elaboramos al relacionar condición étnico-racial y patrimonio (Figura 4 ) deja ver que el 50 por ciento de los vecinos considerados "españoles" con patrimonio declarado tenía fortunas de entre 200 y 1.500 pesos. La misma proporción de "pardos" y "mulatos" tenía patrimonios de entre 100 y 850 pesos; y para el equivalente de los "indios" las fortunas eran de entre 100 y 550 pesos. No se hallaron registros correspondientes a "negros". 
FIGURA 4

Distribución de las fortunas

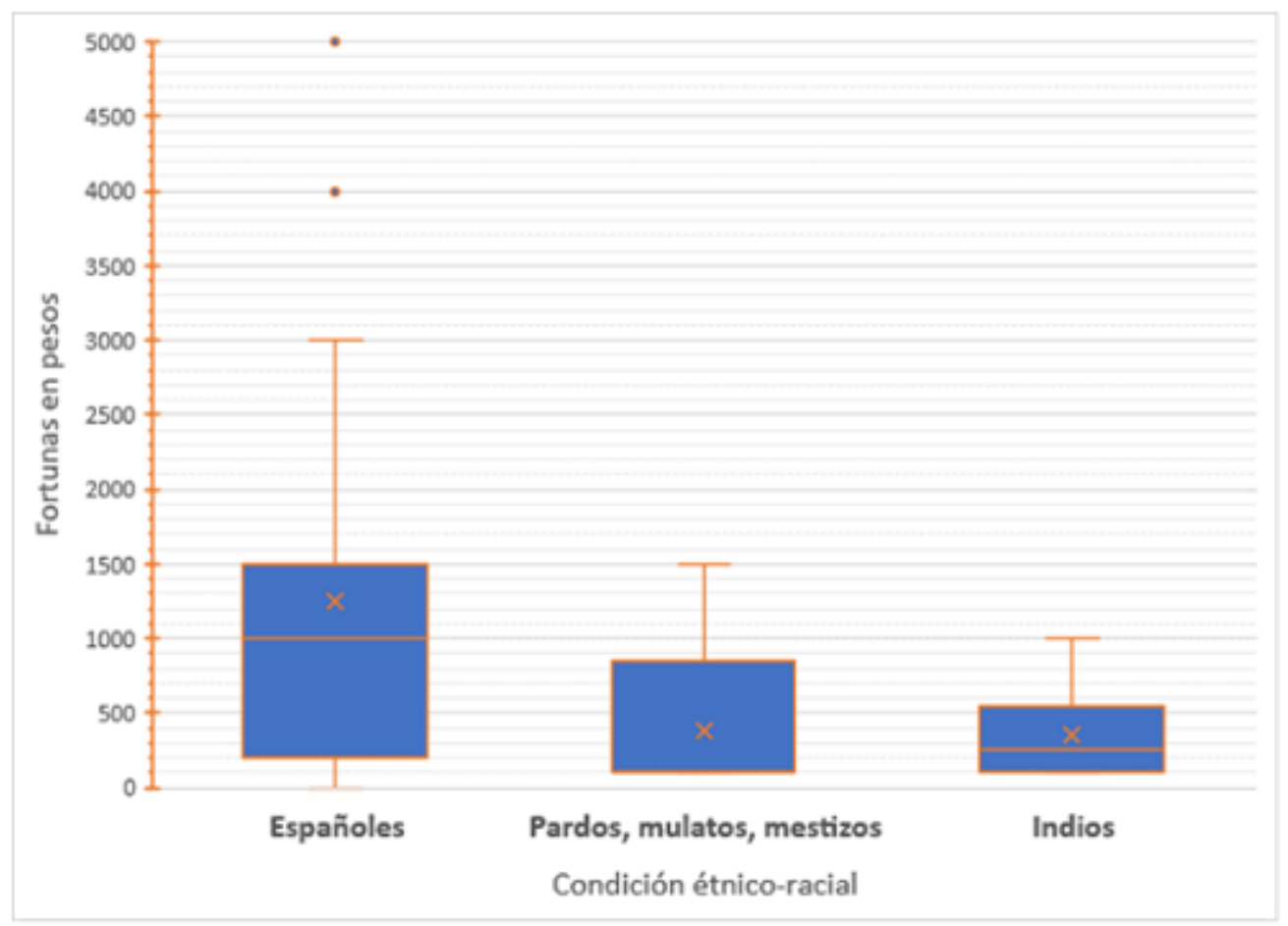

Fuente: Elaboración propia. "Españoles" n= 100. "Mestizos", "pardos” y “mulatos” n= 28. "Indios” n= 6

El promedio de los patrimonios de "españoles" era de casi 1.292 pesos, pero las fortunas presentaban valores atípicos, que oscilaban entre 0,0 pesos asignados a sí mismos por algunos decuriones y un máximo de 40.000 pesos. Se observa mayor dispersión en las fortunas en el caso de los "españoles" que en los "pardos" y "mulatos" y los “indios". El promedio para los vecinos "pardos" y "mulatos" era de 385,7 pesos, con un máximo de 1.500 y un mínimo de 100 pesos. En cambio, para los marcados como "indios” el promedio era de 350 pesos, con un máximo de 1.000 y un mínimo de 100 pesos. El 25 por ciento de los “españoles” con fortunas menores declaró un patrimonio de hasta 200 pesos, mientras que la misma proporción de los "pardos" y "mulatos" y de los "indios" con fortunas pequeñas llegaba a los 100 pesos.

Comadrán Ruiz (1972) observó que en los extramuros de Mendoza predominaban las pequeñas fortunas. En la campaña 229 vecinos reconocieron un patrimonio de 100 pesos pero en la ciudad sólo 67 declararon ese valor. Ese monto, según el autor, podía valer una chacra o una pequeña viña.

Creemos que la movilidad de los considerados "pardos" y "mulatos" y de los "indios" podría ser un factor explicativo del fraccionamiento de la propiedad en la campaña. Aunque la desigualdad entre los considerados “españoles", "pardos" y "mulatos" e "indios" es evidente, había un margen de movilidad que debe observarse no acotando la mirada sólo a las fortunas.

\section{Conclusiones}

Para la campaña mendocina del siglo XIX se ha advertido que la mano de obra estaba sujeta a formas de coacción y control que variaban según el espacio productivo y la distancia con la ciudad (Molina, 2013; Richard Jorba, 2001). Es posible que en el área rural que estudiamos, con muchos cuarteles del oasis norte, relativamente cercanos a la ciudad, la vida rural estuviera bastante vinculada a la urbana y la población esclava y libre circulara entre ambos espacios más de lo que estaban dispuestos a aceptar las autoridades gubernamentales y los propietarios que necesitaban de su mano de obra. Los intentos de extender y reforzar el 
control policial y judicial en la campaña en este período exponen conflictos asociados a esa dinámica (Molina, 2010, 2013).

El dinamismo social, la circulación y los intercambios, en y entre la ciudad y la campaña, podrían deducirse del alcance del mestizaje, especialmente en los sectores bajos. Estos fenómenos, que otrora fueron interpretados por algunos historiadores como factores de retraso de la sociedad civil mendocina (Peña y Lillo, 1937), recientemente fueron resignificados y asociados a las tensiones y la politización posrevolucionaria del bajo pueblo en el Río de la Plata (Molina, 2013).

Este artículo aporta elementos para conocer mejor la dinámica del trabajo y el componente esclavizado en el espacio rural de Mendoza luego de la revolución. Asimismo, permite alumbrar la intervención de diferentes variables sociales y económicas en el acceso a las ocupaciones, la vivienda y la posibilidad de acumular patrimonios.

Los datos indican que el volumen de población esclavizada no era relevante en la campaña como en la ciudad de Mendoza; quizás las levas habían afectado más a los cuarteles de extramuros. El trabajo se sostenía principalmente en la fuerza de los trabajadores libres. La población esclava presentaba un desequilibrio entre sexos que, junto a otros factores que imposibilitaban el crecimiento vegetativo, debió ser definitivo para la declinación de los africanos. Los afrodescendientes criollos libres, en cambio, constituían un grupo en crecimiento desde fines del siglo XVIII. Aunque el padrón de la campaña de 1823 no da cuenta suficiente de este grupo, posiblemente algunos estaban experimentando un proceso de movilidad social que permitía la desmarcación de la esclavitud.

Ser reconocido como "español”, "mestizo", "negro" o "indio" no tenía las mismas implicancias en la campaña mendocina; una síntesis de atributos socialmente construidos ubicaba a las personas en una posición de las jerarquías sociales. Atributos como la condición étnico-racial y las ocupaciones deben pensarse como marcadores sociales dinámicos. También las jerarquías eran dinámicas, y era posible negociarlas y adquirirlas si se disponía de los recursos socialmente admisibles: aprender un oficio, acceder a un trabajo retribuido, constituirse en jefe de familia, acumular haberes, ser propietario de la casa habitación, acumular patrimonios.

Como señalan Faberman y Ratto (2009), a fines de la colonia emergió una sociedad estratificada a partir de criterios socioeconómicos y los descendientes de africanos aprovecharon muy bien los mecanismos de movilidad social que ofrecía la sociedad tardocolonial y, confundidos en "una plebe urbana cada vez más indiferenciada racialmente" (Farberman y Ratto, 2009, p. 20), se apoyaron en el ascenso económico para experimentar un pasaje entre estamentos sociales.

Este trabajo ha permitido explorar, precisamente, cuáles atributos sociales y económicos intervenían en la diferenciación social, especialmente para los afrodescendientes, en la campaña de Mendoza hacia la década de 1820 y cómo era su relación con la posibilidad de obtener marcaciones que indicaban prestigio social. En adelante, los resultados cuantitativos obtenidos podrán beneficiarse de otros aportes de tipo cualitativo que permitan comprender de modo más complejo y profundo el problema.

\section{REFERENCIAS}

Acevedo, E. O. (1981). Investigaciones sobre el comercio cuyano, 1800-1830. Buenos Aires: Academia Nacional de la Historia.

Alberto, P. L. (2020). Liberta por oficio: negociando los términos del trabajo no libre en Buenos Aires en el contexto de la abolición gradual, 1820-1830. En F. Guzmán y M. de L. Ghidoli (Eds.), El asedio a la libertad: abolición y posabolición de la esclavitud en el Cono Sur (1 ${ }^{\mathrm{a}}$ ed.). [EPub]. Buenos Aires: Biblos. URL: https://biblos.publica.la/reader/el-asedio-a-la-libertad-1599657785?location=eyJjaGFwdGVySHJlZiI6 ImlkLTAyNSIsImNmaSI6Ii80LzIvMi8xOjAifQ==

Andrews, G. R. (1989). Los afroargentinos de Buenos Aires. Buenos Aires: Ediciones De la Flor.

Bernand, C. (2001). Negros esclavos y libres en las ciudades hispanoamericanas. Madrid: Fundación Histórica Tavera. 
Candioti, M. (2016). Abolición gradual y libertades vigiladas en el Río de la Plata. La política de control de libertos de 1813. Corpus, 6(1), 1-14.

Comadrán Ruiz, J. (1969). Evolución demográfica argentina durante el periodo hispano (1535-1810) (1a ed.). Buenos Aires: EUDEBA.

Comadrán Ruiz, J. (1972). Algunos aspectos de la estructura demográfica y socioeconómica de Mendoza hacia 1822-24. Historiografia y Bibliografia Americanista, 16 (1), 1-28.

Cosamalón Aguilar, J. A. (2017). El juego de las apariencias: la alquimia de los mestizajes y las jerarquias sociales en Lima, siglo XIX. Ciudad de México: El Colegio de México; Lima: IEP Instituto de Estudios Peruanos.

Cremaschi, M. (1989). Aspectos socio-demográficos de Mendoza entre 1800-1840 a través de registros parroguiales (libros de matrimonios). Revista de Historia Americana y Argentina, XV (29-30), 235-254.

Farberman, J., y Ratto, S. (2009). Historias mestizas en el Tucumán colonial y las pampas (siglos XVII-XIX). Buenos Aires: Biblos.

Garavaglia, J. C. (1999). Pastores y labradores de Buenos Aires. Una historia agraria de la campaña bonaerense 1700-1830. Buenos Aires: De la Flor.

Garavaglia, J. C. (2013). The Economic Role of Slavery in a Non-Slave Society: The River Plate, 1750-1860. En J. M. Fradera y C. Schmidt-Nowara (Eds.), Slavery and Antislavery in Spain's Atlantic Empire (1a ed., p. 340). Brooklyn, New York: Berghahn Books.

Garavaglia, J. C., y Prieto, M. del R. (2007). Diezmos, producción agraria y mercados: Mendoza y Cuyo, 1710-1830. Boletín del Instituto de Historia Argentina y Americana Dr. Emilio Ravignani, 30, 1-12.

Ghirardi, M., Colantonio, S., y Celton, D. E. (2010). De azabache y ámbar. Tras las huellas de los esclavos de Córdoba al despuntar la revolución. En S. Mallo y I. Telesca (Eds.), "Negros de la patria" Los afrodescendientes en las luchas por la independencia en el antiguo virreinato del Rio de la Plata (pp. 89-112). Buenos Aires: SB.

Goldberg, M. B., y Mallo, S. (2005). Trabajo y vida cotidiana de los africanos en Buenos Aires 1750-1850. En M. B. Goldberg (Ed.), Vida cotidiana de los negros en hispanoamérica (pp. 17-39). Madrid: Larramendi; Madrid: Fundación MAPFRE Tavera.

Guzmán, F. (2013). Performatividad social de las (sub)categorías coloniales Mulatos, pardos, mestizos y criollos en tiempos de cambios, guerra y política, en el interior de la Argentina. En F. Guzmán y L. Geler (Eds.), Cartografías afrolatinoamericanas: perspectivas situadas para análisis transfronterizos (pp. 57-83). Buenos Aires: Biblos.

Halperin Donghi, T. (2014). Revolución y Guerra. Formación de una élite dirigente en la Argentina criolla ( $3^{a}$ edición). Buenos Aires: Siglo Veintiuno Editores.

Johnson, L. L. (2013). Los talleres de la revolución. Buenos Aires: Prometeo.

Lacoste, P. (2009). Transporte terrestre en el Cono Sur (1550-1850): Arrieros y troperos. Si Somos Americanos, Revista de Estudios Transfronterizos, $I X(2), 141-168$.

Masini Calderón, J. L. (1962). La esclavitud negra en Mendoza. Época independiente. Mendoza: D'Accurcio.

Masini Calderón, J. L. (1963). La esclavitud negra en San Juan y San Luis. Época independiente. Revista de Historia Americana y Argentina, $I V(7 / 8), 177-210$.

Molina, E. (2007). Justicia y poder en tiempos revolucionarios\#: las modificaciones en las instituciones judiciales subalternas de mendoza (1810-1820). Revista de Historia del Derecho, 35, 269-296.

Molina, E. (2013). Los tentáculos de la justicia: Equipamiento institucional para gobernar la campaña y la frontera a fines del período colonial, Mendoza, 1780-1810. En M. Gascón y M. J. Ots (Eds.), Fronteras y periferias en arqueologia e historia (pp. 159-194). Buenos Aires: Dunken.

Moreno, J. L. (1989). Población y sociedad en el Buenos Aires rural a mediados del siglo XVIII. Desarrollo Económico, 29(114), 265-282.

Peña y Lillo, S. (1937). Los gobernadores de Mendoza. Mendoza: Best.

Richard Jorba, R. A. (1998). Poder, economia y espacio en Mendoza: 1850-1900. Del comercio ganadero a la agroindustria vitivinicola. Mendoza: Ed. de la Facultad de Filosofía y Letras, UNCuyo. 
Richard Jorba, R. A. (2001). Transiciones económicas y formación del mercado de trabajo libre en Mendoza. El trabajo rural entre la segunda mitad del siglo XIX y los albores del XX. En $5^{\circ}$ Congreso Nacional de Estudios del Trabajo de la Asociación Argentina de Especialistas en Estudios del Trabajo (ASET), Buenos Aires, 1 al 3 de agosto de 2001.

Valenzuela Márquez, J. (2007). La cordillera de los Andes como espacio de circulaciones y mestizajes: un expediente sobre Chile central y Cuyo a fines del siglo XVIII. Nuevo Mundo Mundos Nuevos [Online], Debates, Online desde el 10 de julio de 2007, recuperado el 14 de septiembre de 2021. URL: http://journals.openedition.org/ nuevomundo/7102

Zamora, R. (2010). Acerca de las discusiones sobre el salario de las criadas. Algunas reflexiones sobre el orden jurídico local en San Miguel de Tucumán a fines del siglo XVIII. Revista de Historia del Derecho, 39, 1-20.

\section{Notas}

1 AGPM, Época Independiente, Sección Gobierno "Censos”, Carpeta no 14 y Carpeta n 15 B; AGPM, Época Independiente, Sección Hacienda, Carpeta $\mathrm{n}^{\circ} 384$, Documento $\mathrm{n}^{\circ} 10$, "Padrón de los haberes y propiedades del vecindario de esta capital, formado por un cálculo prudente, moderado y equitativo", s.f. [ca. 1823], fs. 24.

2 La cantidad de cuarteles urbanos y rurales figura en el Padrón de haberes y propiedades de los vecinos de Mendoza de ca. 1823. Su ubicación en el plano de Mendoza (Figura 1) es tentativa, ya que no hay una fuente que indique la disposición de los cuarteles en el espacio para 1823. El investigador Luis César Caballero ha encontrado en el AGPM un padrón de la villa de San Carlos catalogado sin fecha y sin numeración de cuartel, que según sus triangulaciones con fuentes parroquiales sería del año 1823; y que no ha sido considerado en este trabajo ni en los de Masini (1962) y Comadrán Ruiz (1972). Agradecemos a Caballero su aporte para determinar la fecha de elaboración de algunos padrones catalogados sin fecha en el AGPM.

3 La figura del decurión se creó en Mendoza en 1811 con funciones de justicia y policía en los cuarteles. La subdivisión de la ciudad y campaña en cuarteles se dispuso en 1810 luego de la revolución (Molina, 2007).

4 La categoría colonial de "calidad" ponía en el centro de la producción de diferencias sociales al color y el origen de las personas. Sintetizaba un conjunto de atributos como la "pureza de sangre", el linaje, el color de la piel, el estatus económico, la ocupación y el lugar de residencia (Cosamalón Aguilar, 2017; Guzmán, 2013). Las fuentes indican que en las primeras décadas del siglo XIX en Mendoza esa categoría todavía se usaba, pero el hecho de que la Sala de Representantes de Mendoza no haya solicitado ese registro en 1823 y de que sólo una parte de los decuriones que elaboraron los padrones la haya empleado es indicio de que estaba perdiendo eficacia simbólica, aunque no había desaparecido completamente.

5 Por el uso social ambiguo de la categoría, que ya señalamos, puede ser que en el grupo que definimos como libertos hayan quedado comprendidos algunos hijos de madres afrodescendientes libres que, sin ser alcanzados por la ley de vientres, fueron anotados con el término que correspondía a estos últimos.

6 Con el propósito de simplificar las categorías se agruparon algunos valores: "sitio mediano" y "sitio regular", en "sitio"; "sitiecito", "sitiecito corto" y "sitio muy pequeño", en "sitio pequeño". 